\title{
Evaluation of the Intrinsic Crack Growth Rates of Weld Joints
}

\author{
Xiang Zhang ${ }^{1 *}$, Rui Bao ${ }^{2}$ \\ ${ }^{1}$ Department of Aerospace Engineering, School of Engineering, Cranfield University, \\ Bedford, MK43 0AL, U.K. \\ ${ }^{2}$ Institute of Solid Mechanics, School of Aeronautic Science and Engineering, \\ Beihang University, Beijing, 100191, China
}

\begin{abstract}
:
A method is presented for evaluating the intrinsic fatigue crack growth rate (FCGR) by excluding the effect of welding-induced residual stresses. Calculation procedures have been developed and demonstrated via an example of crack growth across a longitudinal weld subjected to constant amplitude loads and also constant applied stress intensity factor ranges. Trends of intrinsic FCGR in different weld regions are identified. The methodology should also be applicable for crack propagation within and parallel to a weld for establishing intrinsic FCGR laws.
\end{abstract}

Keywords: welded joints; crack growth; residual stresses; weld intrinsic property.

\section{Nomenclature}

$a \quad$ half or full crack length in centre crack or edge crack geometry

$A_{1}, \ldots, A_{\mathrm{n}} \quad$ base material constants in general form of crack growth laws

$A_{1}^{\prime}, \ldots, A_{n}^{\prime} \quad$ weld metal constants in general form of crack growth laws

$C, m, n \quad$ material constants in the Walker Equation

$C_{b}, m_{b}, n_{b} \quad$ base material constants in the Walker Equation

$C_{w}, m_{w}, n_{w} \quad$ weld metal constants in the Walker Equation

$E, G, v \quad$ Young's modulus, Shear modulus, Poisson's ratio

$K_{\text {app }}, K_{\text {res }}, K_{\text {tot }}$ stress intensity factor (SIF) due to applied, residual and combined stress fields

$K_{a p p, \max }, K_{t o t, \max }$ SIF due to applied and combined stress fields at the maximum applied stress

$K_{a p p, \min }, K_{t o t, \min }$ SIF due to applied and combined stress fields at the minimum applied stress

$\Delta K_{\text {app }}, \Delta K_{\text {tot }} \quad$ SIF range due to applied and combined applied and residual stresses

$R \quad$ nominal stress intensity factor ratio $\left(K_{\min } / K_{\max }=\sigma_{\min } / \sigma_{\max }\right)$

$R_{\text {eff }} \quad$ effective stress intensity factor ratio $\left(K_{t o t, \min } / K_{\text {tot, } \max }\right)$

$W \quad$ half width of centre crack or full width of edge crack specimen

$\beta \quad$ non-dimensional SIF

$\Delta \sigma_{a p p}, \sigma_{a p p \max }$ applied stress range and maximum stress

$\sigma_{\text {res }}(x) \quad$ residual stress distribution

$(d a / d N)_{b},(d a / d N)_{w}$ fatigue crack growth rate (FCGR) in base material and weld metal

$(d a / d N)_{R} \quad$ FCGR in weld metal with residual stress effect only (no material change)

$(d a / d N)_{\text {int }} \quad$ intrinsic FCGR in weld metal without residual stress effect

\footnotetext{
* Corresponding author. Tel.: +44 1234 754621; fax: +44 1234758203.

Email address: xiang.zhang@cranfield.ac.uk (X. Zhang)
} 


\section{Introduction}

Significant amount of research has been conducted in the past 20 years to understand the damage tolerance properties of fusion, laser and friction stir welds in aerospace aluminium alloys [1-9]. One of the key damage tolerance requirements is the capability of predicting fatigue crack growth life. Comparing with the base material (BM), changes in crack growth rates in weld metal (WM) arise from two main factors, one is the welding-induced residual stresses and the other is the change in weld metal properties due to the microstructural changes. However, current predictive models uses the base material fatigue crack growth rate (FCGR) and consider only the residual stress to predict weld plate life; changes in weld metal properties are not counted in these predictive models [e.g. 3, 9-12]. The main reason for this is the lack of weld metal crack growth rate properties.

For crack propagation perpendicular to a weld, welding-induced residual stresses are found to play a major role on the FCGR $[1,7,8]$. Effects of residual stress and microstructural changes on FCGR were investigated in friction stir welded AA2050 [7] and AA2024 alloys [8]. The tests were conducted on compact tension specimens subject to constant values of applied stress intensity factor range. Both studies have concluded that residual stress is the main influential factor, but in the weld nugget microstructural effect is also present. In [8], effect of microstructural and hardness changes on FCGR was observed by relieving weld residual stresses. The test specimen was stretched parallel to the weld centreline to a $2 \%$ plastic strain. It was observed that crack growth rates outside the weld rose to the values expected for the BM. Since no difference was found in the hardness and microstructure before and after the residual stress relief, it was concluded that residual stress redistribution after the mechanical tensioning was responsible for the difference in crack growth rates. However, no quantitative analysis has been performed on the influence of each factor.

For crack propagation within and parallel to a weld, crack growth rates have been found to be considerably lower than that in the base material $[5,13]$. A detailed FE model was used to simulate crack path deviation in weld by employing different material properties for the base material and weld metal [14]. However, no method has been found in the open literature for predicting fatigue crack growth behaviour within a weld. An approximate method is to use the weld metal FCGR measured from test coupons (instead of using the base material FCGR and adding residual stresses) to predict the life of a welded component that is manufactured by the same welding process. Using this method the effects of residual stress and microstructural changes are both included in the coupon test data. However, the predicted crack growth rates can be sensitive to the difference in specimens' geometry and dimension.

It is well-known that residual stress magnitude and distribution are different for different dimensions, but the weld metal microstructural change should be the same for the same welding process parameters even though the dimensions of the test coupon and component are different. Therefore, if the influences of residual stress and weld microstructure change on FCGR can be separated, that is if the FCGR in a weld can be determined without the influence of residual stress, then it is possible to evaluate the influence of the weld material intrinsic property on the FCGR. This growth rate property should be unique for each welding process and independent of weld sample geometry and residual stress, therefore it can be used in conjunction with either measured or calculated residual stresses for predicting crack growth life of a give component (using coupon test data). In this paper we refer this property as the "weld intrinsic crack growth rate".

The objective of this paper is to present a method to extract the weld intrinsic crack growth rate from test measured crack growth rate. The idea is that, if it is possible to separate the contribution of welding-induced residual stress from measured crack growth rates, then the rest in the growth rate change is due to the contribution from weld metal microstructural changes. First, fracture mechanics analysis is performed to determine the residual stress effect 
on FCGR in the base material. This is followed by a series of calculations to extract the weld intrinsic crack growth rates from measured FCGR. An example is used to demonstrate the methodology and analysis procedure.

\section{Methodology}

\subsection{The concept}

In the presence of residual stresses, the total stress intensity factor range and effective stress intensity factor ratio due to the combined stresses can be calculated by the superposition rule $[15,16]$ :

$$
\begin{gathered}
\Delta K_{t o t}=K_{t o t \max }-K_{t o t \min }=\left(K_{a p p \max }+K_{r e s}\right)-\left(K_{a p p \min }+K_{r e s}\right)=\Delta K_{a p p} \\
R_{e f f}=\frac{K_{a p p \min }+K_{r e s}}{K_{a p p \max }+K_{r e s}}
\end{gathered}
$$

It can be seen that $\Delta K_{\text {tot }}$ is the same as $\Delta K_{\text {app }}$, but $R_{\text {eff }}$ is different from the nominal ratio $R$. In the framework of linear elastic fracture mechanics (LEFM), numerous crack growth rate laws have been developed to correlate FCGR $(d a / d N)$ with the stress intensity factor range $\Delta K$ [12-13]. The general form of these laws can be expressed by eq. (3), where $A_{1}, \ldots, A_{n}$ are material constants of the base material, $\Delta K_{a p p}$ and $R$ reflect the applied stress and specimen geometry.

$$
\left(\frac{d a}{d N}\right)_{b}=f\left(\Delta K_{a p p}, R, A_{1}, \cdots, A_{n}\right)
$$

When the crack growth law is applied to calculate crack growth rates of welded samples, $\Delta K_{a p p}$ and $R$ are replaced by $\Delta K_{t o t}$ and $R_{e f f}$ to include welding-induced residual stresses; $A_{1}, \ldots, A_{n}$ should be replaced by $A_{1}^{\prime}, \ldots, A_{n}^{\prime}$, which are material constants of the weld sample.

$$
\left(\frac{d a}{d N}\right)_{w}=f\left(\Delta K_{t o t}, R_{e f f}, A_{1}^{\prime}, \cdots, A_{n}^{\prime}\right)
$$

The difference in the FCGR between the weld metal and base material is:

$$
\Delta=\left(\frac{d a}{d N}\right)_{w}-\left(\frac{d a}{d N}\right)_{b}
$$

This difference contains contributions from the weld residual stresses and material property changes in the weld. Assume that the welding process induces only the residual stress without changing the material properties, the corresponding FCGR should be:

$$
\left(\frac{d a}{d N}\right)_{R}=f\left(\Delta K_{t o t}, R_{e f f}, A_{1}, \cdots, A_{n}\right)
$$

The increment in FCGR caused by residual stress effect is:

$$
\Delta_{1}=\left(\frac{d a}{d N}\right)_{R}-\left(\frac{d a}{d N}\right)_{b}
$$

Since $\Delta_{1}$ should be different from $\Delta$, define $\Delta_{2}$ as the difference due to the contribution of weld material change without the influence of residual stress:

$$
\Delta_{2}=\Delta-\Delta_{1}
$$

Therefore, the intrinsic crack growth rate in weld metal is:

$$
\left(\frac{d a}{d N}\right)_{\mathrm{int}}=\left(\frac{d a}{d N}\right)_{b}+\Delta_{2}
$$


Fig. 1 shows schematically the changes in FCGR consisting of the increment $\Delta_{1}$ arising from residual stresses and $\Delta_{2}$ due to weld material property change. These increments, $\Delta, \Delta_{1}$ and $\Delta_{2}$, can be either positive or negative and may not always be the same with the increase of $\Delta K$.

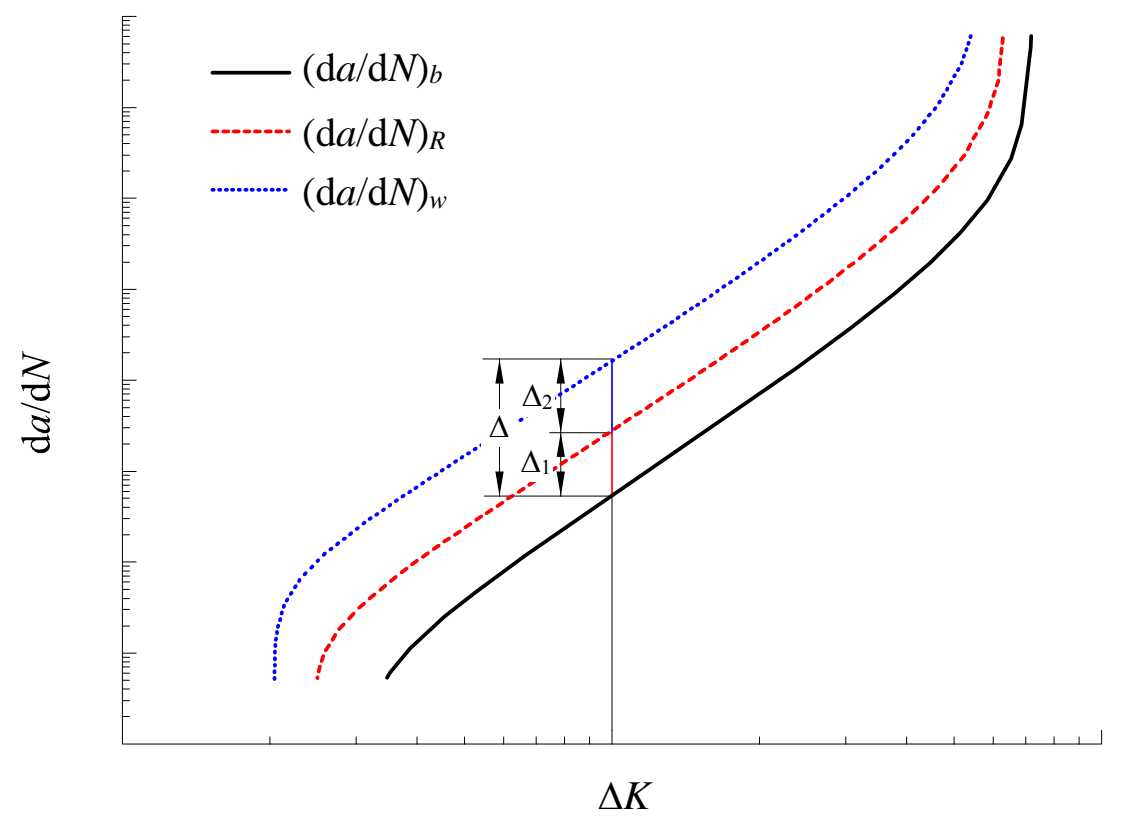

Fig. 1 Schematic of contribution of weld residual stress and material property change to FCGR in weld metal

Substitute eqs. (5), (7) and (8) into eq. (9), find:

$$
\begin{aligned}
\left(\frac{d a}{d N}\right)_{\mathrm{int}} & =\left(\frac{d a}{d N}\right)_{b}+\left\{\left[\left(\frac{d a}{d N}\right)_{w}-\left(\frac{d a}{d N}\right)_{b}\right]-\left[\left(\frac{d a}{d N}\right)_{R}-\left(\frac{d a}{d N}\right)_{b}\right]\right\} \\
& =\left(\frac{d a}{d N}\right)_{b}+\left(\frac{d a}{d N}\right)_{w}-\left(\frac{d a}{d N}\right)_{R}
\end{aligned}
$$

Data $(d a / d N)_{\text {int }}$ can be determined from eq. (10) using test measured data $(d a / d N)_{b}$ and $(d a / d N)_{w}$ and calculated $(d a / d N)_{R}$.

On the other hand, $(d a / d N)_{\text {int }}$ can also be expressed as a function of the applied stress and specimen geometry parameters $\left(\Delta K_{a p p}, R\right)$ and the material constants for weld metal $\left(A_{1}^{\prime}, \ldots, A_{n}^{\prime}\right)$ :

$$
\left(\frac{d a}{d N}\right)_{\mathrm{int}}=f\left(\Delta K_{a p p}, R, A_{1}^{\prime}, \cdots, A_{n}^{\prime}\right)
$$

Then, constants $\left(A_{1}^{\prime}, \ldots, A_{n}^{\prime}\right)$ can be determined by fitting the $(d a / d N)_{\text {int }}$ data that is obtained from eq. (10).

It should be pointed out that, since there are many established crack growth laws, the $f$ function in eqs. (3), (4) and (11) can be different. The choice of crack growth laws will not affect the concept of this method for extracting intrinsic crack growth rate from test data of weld samples with residual stress in presence. However, for the evaluation purpose it will be convenient to use the same crack growth law through the analysis procedure.

The entire procedure is summarised in the flow chart in Fig. 2. 


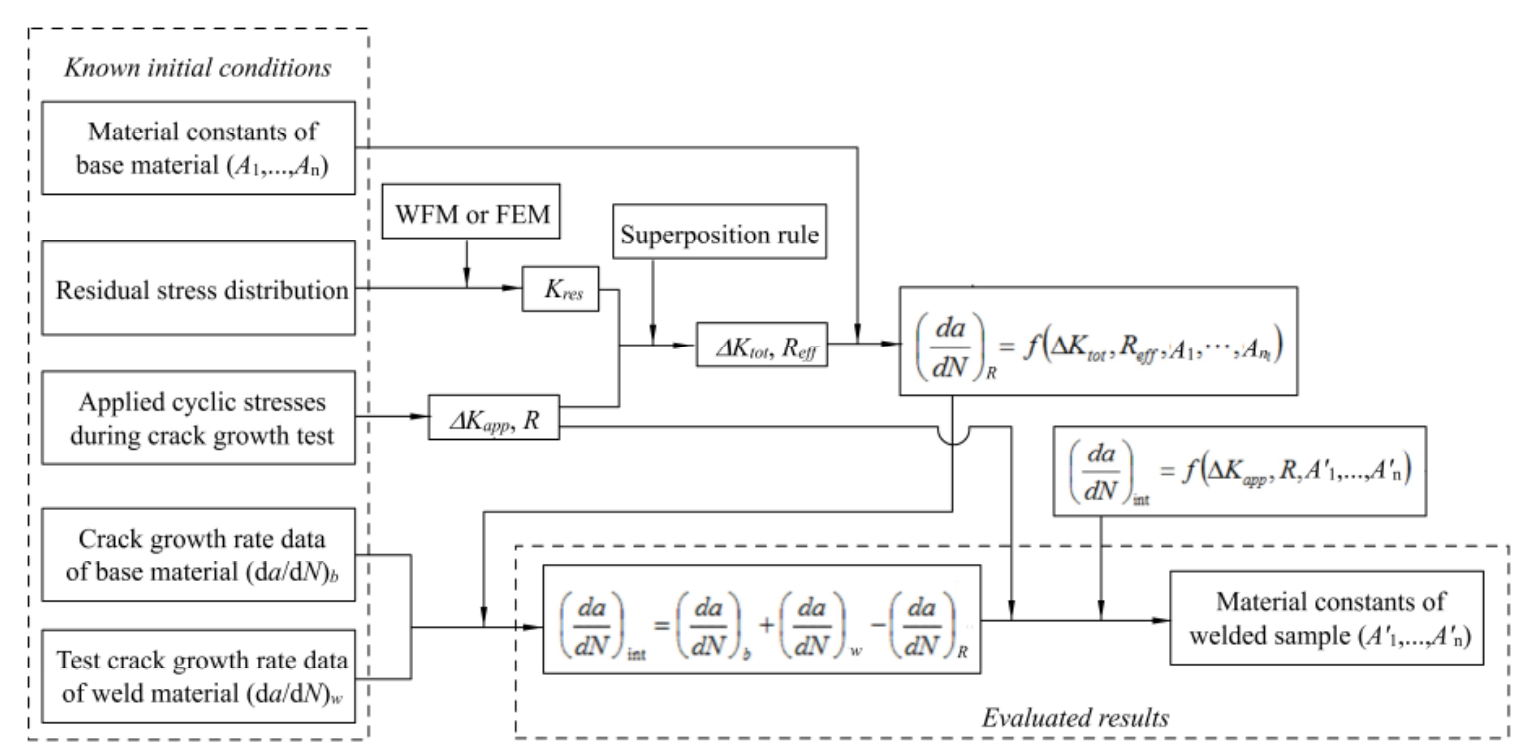

Fig. 2 Flow chart of the proposed procedure for evaluating weld intrinsic FCGR

\subsection{Method and Procedure}

To take into account of the residual stress effect, the effective ratio $R_{\text {eff }}$ defined in eq. (2) must be one of the parameters in the selected crack growth rate law. Established empirical laws, such as the equations proposed by Walker (Eq. 12) [17, 18] and Forman (Eq. 13) [19], and the NASGRO equation (Eq. 14) [18] all contain the $R$ ratio variable.

$$
\begin{gathered}
\frac{d a}{d N}=C\left[\Delta K(1-R)^{m-1}\right]^{n} \\
\frac{d a}{d N}=\frac{C(\Delta K)^{n}}{K_{c r i t}(1-R)-\Delta K} \\
\frac{\mathrm{d} a}{\mathrm{~d} N}=C\left[\left(\frac{1-f}{1-R}\right) \Delta K\right]^{n} \frac{\left(1-\frac{\Delta K_{t h}}{\Delta K}\right)^{p}}{\left(1-\frac{K_{\max }}{K_{c r i t}}\right)^{q}}
\end{gathered}
$$

where, $C, n, m, p, q, K_{c r i t}, \Delta K_{\text {th }}$ are all material constants, $f$ is a parameter correlating with the ratio $R$.

According to the LEFM theory [20], $\Delta K$ is a function of crack length $a$ :

$$
\Delta K=\beta \cdot \Delta \sigma \sqrt{\pi a}
$$

Therefore, for the base material $d a / d N$ can be expressed as function of $a$ :

$$
\left(\frac{d a}{d N}\right)_{b}=f_{1}\left(a, \Delta \sigma, \beta_{1}\right)
$$

where $\beta_{1}$ is a geometry factor of the test specimen made of the base material.

Since the crack growth rate data of welded sample, $(d a / d N)_{w}$, can be derived from the differential of test measured $(a, N)$ data, denote:

$$
\left(\frac{d a}{d N}\right)_{w}=f_{2}\left(a, \Delta \sigma, \beta_{2}\right)
$$

where $\beta_{2}$ is a geometry factor of the weld metal test specimen. 
In this study the residual stress intensity factor, $K_{\text {res }}$, is obtained by FE analysis, and can be reasonably expressed as function of crack length, residual stress and specimen geometry. Hence, both $\Delta K_{\text {tot }}$ and $R_{e f f}$ in Eq. (6) are functions of $a$, accordingly, $(d a / d N)_{R}$ can be expressed as a function of the crack length:

$$
\left(\frac{d a}{d N}\right)_{R}=f_{3}\left(a, \Delta \sigma, \beta_{3}\right)
$$

where $\beta_{3}$ is a factor associated with the weld metal test specimen geometry and the weld location.

From Eq. (10), the weld intrinsic crack growth data $\left((d a / d N)_{\text {int }}, a\right)$ can be obtained by the following equation:

$$
\left(\frac{d a}{d N}\right)_{\text {int }}=f_{1}\left(a, \Delta \sigma, \beta_{1}\right)+f_{2}\left(a, \Delta \sigma, \beta_{2}\right)-f_{3}\left(a, \Delta \sigma, \beta_{3}\right)
$$

For the case of using the identical geometry for testing base material and weld metal, it is more convenient to use a set of $d a / d N$ data to get $(d a / d N)_{\text {int }}$ :

$$
\left.\left(\frac{d a}{d N}\right)_{\text {int }}\right|_{a=a_{i}}=\left.\left(\frac{d a}{d N}\right)_{b}\right|_{a=a_{i}}+\left.\left(\frac{d a}{d N}\right)_{w}\right|_{a=a_{i}}-\left.\left(\frac{d a}{d N}\right)_{R}\right|_{a=a_{i}}
$$

This set of weld intrinsic crack growth rate data can also be correlated by a crack growth rate law. For demonstration purpose, the Walker equation is employed here:

$$
\begin{aligned}
\left(\frac{d a}{d N}\right)_{\text {int }} & =C_{w}\left[\Delta K_{a p p}(1-R)^{m_{w}-1}\right]^{n_{w}} \\
& =\left(C_{w}(1-R)^{\left(m_{w}-1\right) n_{w}} \Delta \sigma_{a p p}^{n_{w}}\right) \cdot(\beta \sqrt{\pi a})^{n_{w}}
\end{aligned}
$$

Material constants, $C_{w}, m_{w}, n_{w}$, which describe the weld intrinsic crack growth rates, can be obtained by fitting the $\left((d a / d N)_{\text {int }}, a\right)$ data obtained from Eq. (20) using the expression of Eq. (21).

\section{Intrinsic crack growth rate of a longitudinal weld}

\subsection{Variable Polarity Plasma Arc welding}

The Variable Polarity Plasma Arc (VPPA) welding process was firstly investigated in 1940s and developed extensively in 1980s by the NASA for achieving high quality aluminium welds [21]. During the welding process, the molten pool and the heat input produce significant metallurgical changes compared with the base material. Due to the availability of residual stress and FCGR test data, 2024-T3 VPPA weld is used as a demonstration example. Specimen geometry is shown in Fig. 3a and micrograph of the interdentric structure in the fusion zone (FZ) and heat affected zone (HAZ) is shown in Fig. 3b. For this configuration, crack grows across the fusion zone, heat affected zone and base material. The hardness in the FZ, where the molten material is solidified, is the lowest as this area contains a fairly coarse dendritic structure with little precipitation hardening [22]. Material in the HAZ has been thermally treated by the heat input during welding. These microstructure changes result in different crack growth rates comparing with that of the base material. Procedures for evaluating the intrinsic crack growth rate are described in the following sections.

\subsection{Initial conditions}

Evaluation of the weld intrinsic crack growth rate of a VPPA welded 2024-T351 specimen is based on the test data reported in $[9,23]$. The specimen configuration is shown in Fig. 3a. Measured longitudinal residual stresses shown in Fig. 4 and measured crack growth rates are 
taken from $[9,23]$. The loading conditions are summarised in Table 1. Crack growth rates of the base material of 2024-T351 of L-T orientation are taken from [18]. Measured crack growth rates for the base material and weld specimens are shown in Section 3.4 together with the evaluated weld metal intrinsic FCGR.

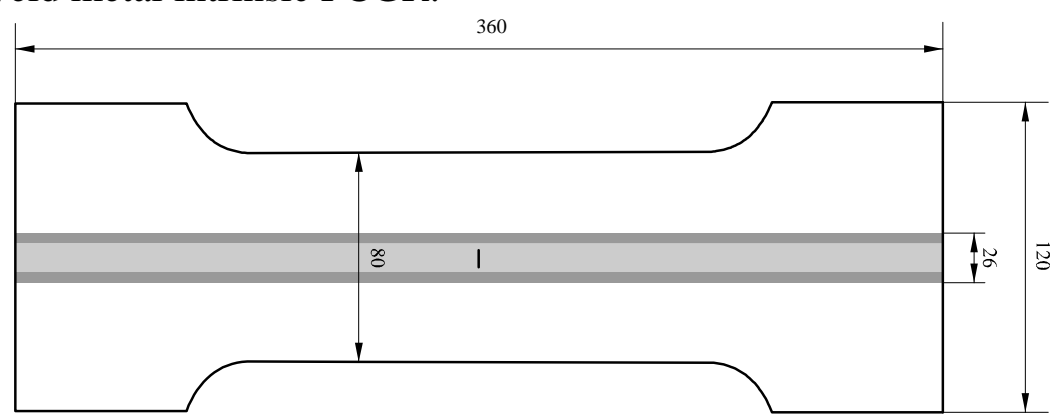

(a)

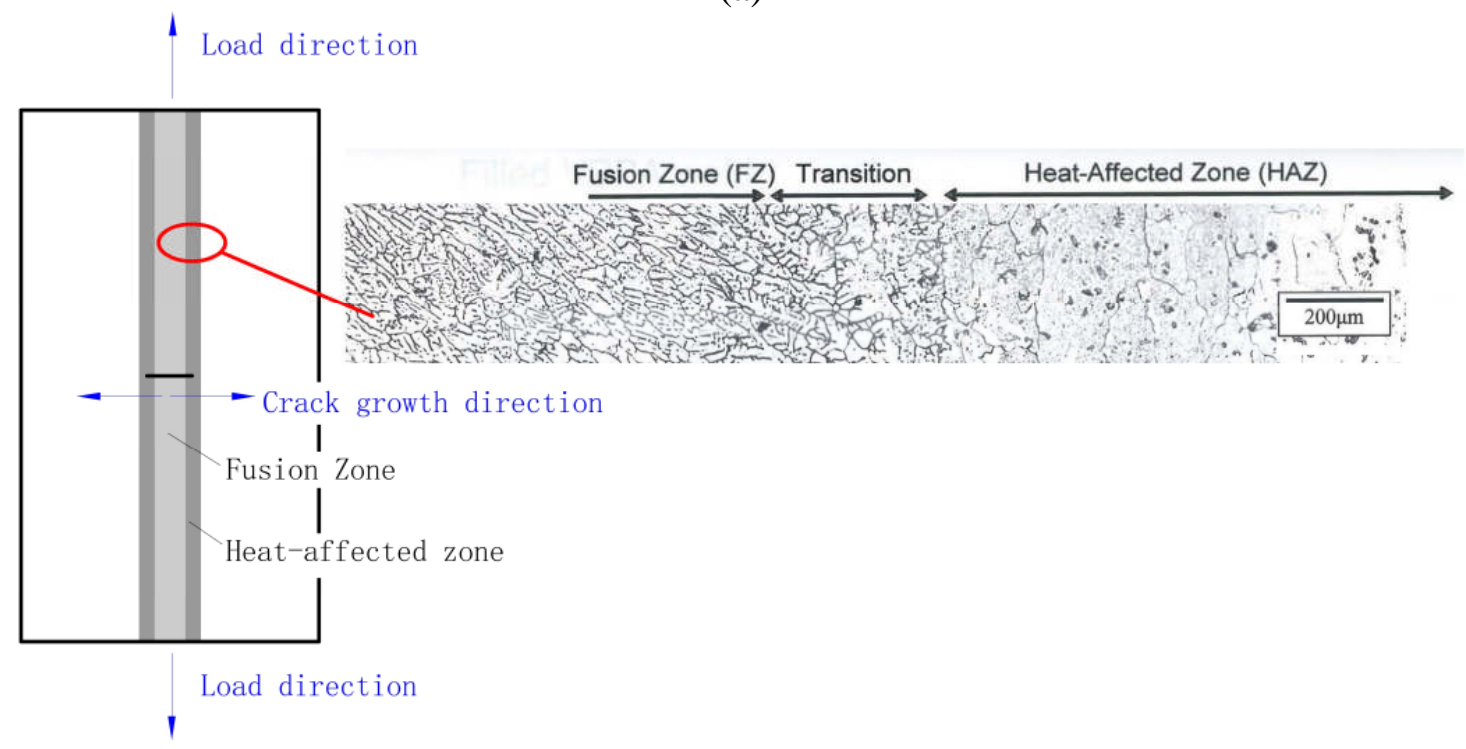

(b)

Fig. 3 Configuration of (a) the test specimen (unit: $\mathrm{mm}$ ) and (b) crack growth path in longitudinal weld specimen (micrograph of the interdendritic structure is taken from [22])

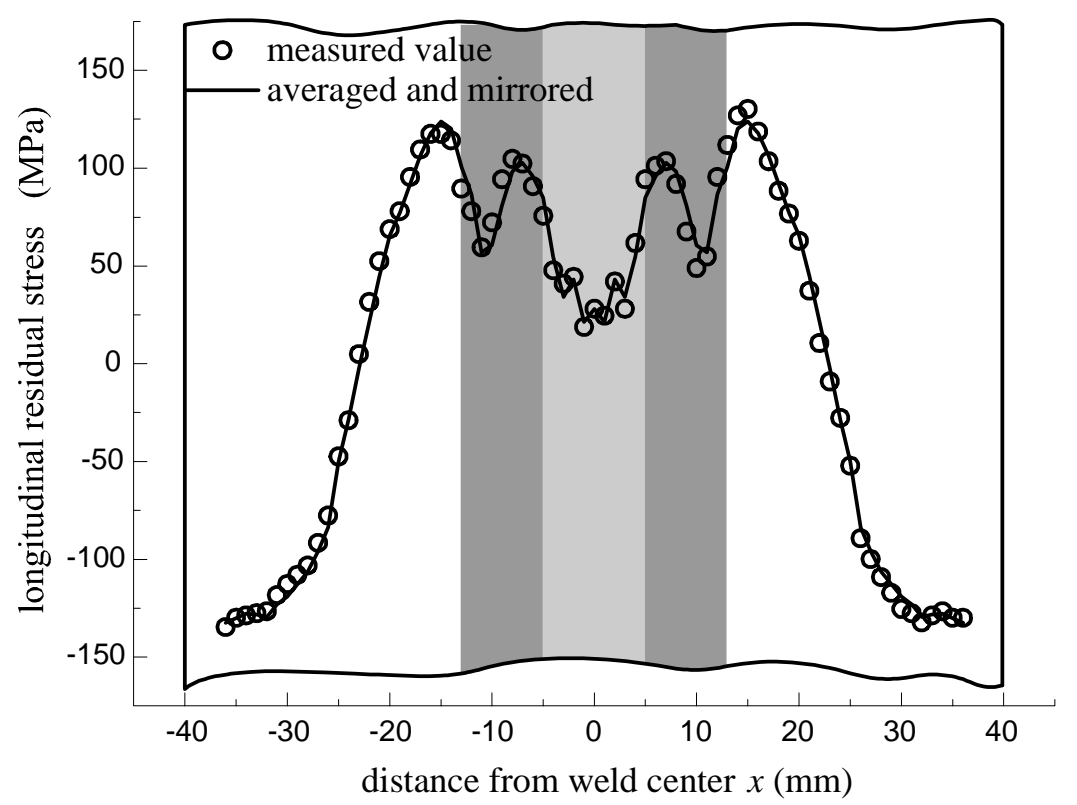

Fig. 4 Distribution of longitudinal residual stresses 


\subsection{Calculation of $\boldsymbol{K}_{\text {res }}$}

Stress intensity factor $\left(K_{\text {res }}\right)$ due to a given residual stress field is calculated by the finite element method (FEM) using the displacement extrapolation method. The calculation needs not to be done manually as the procedure is now implemented in some commercial FE packages. In this study, the ANSYS package is used to computer the $K_{\text {res }}$ by calling the command "KCALC" in the general postprocessor after defining the path for extracting crack region displacements. For the calculation purpose, measured residual stresses are averaged and mirrored with respect to the weld centreline (Fig. 4), before being inputted into the FE model. Details of the FE analysis can be found in [24].

Calculated $K_{\text {res }}$ is presented in Fig. 5. For the convenience of further analysis, calculated values are fitted by the Gaussian equation, eq. (22). The fitting curve is also shown in Fig. 5.

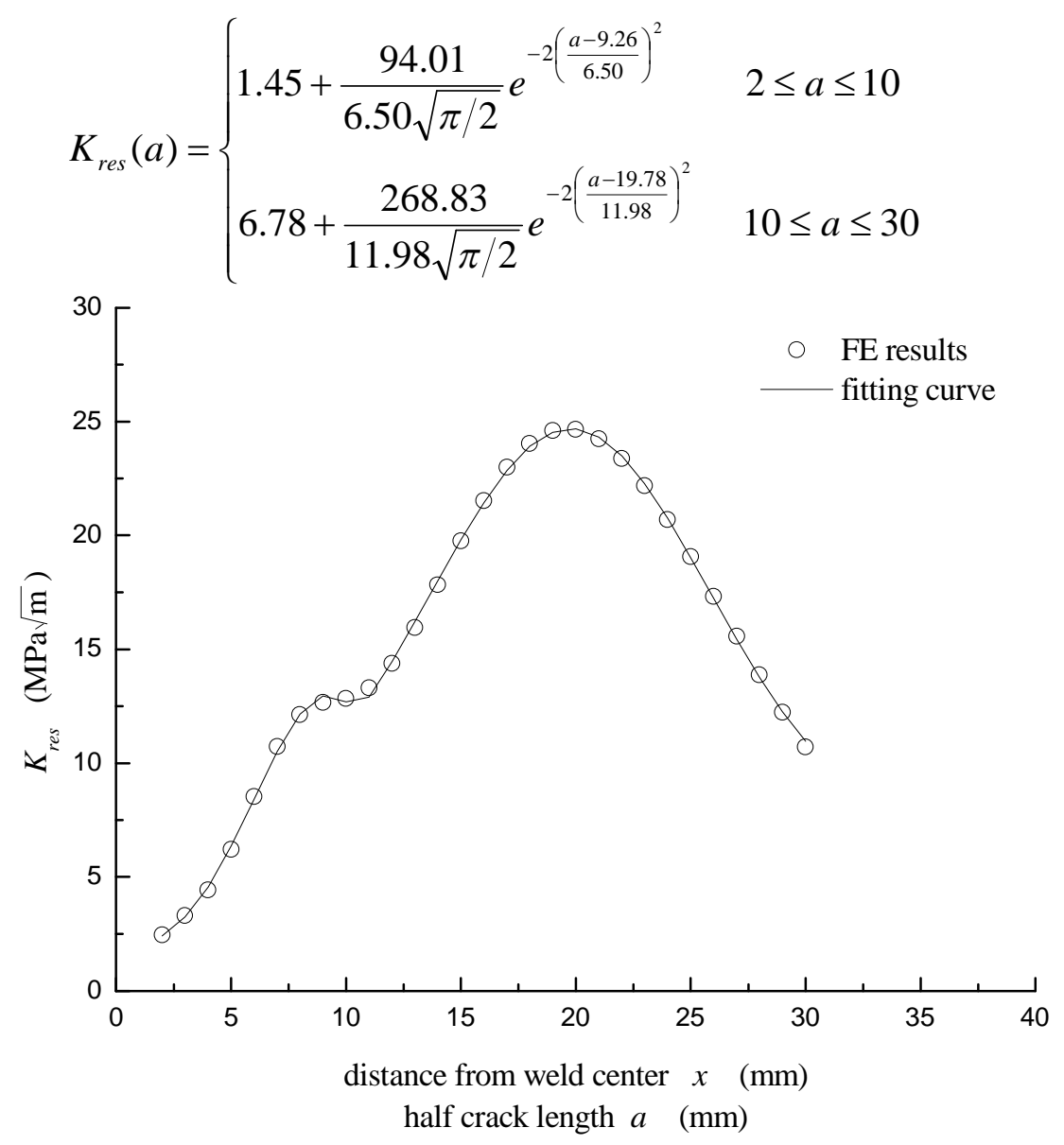

Fig. 5 Calculated $K_{\text {res }}$ by FEM and fitting curve

\subsection{Determination of $(d a / d N)_{\text {int }}$}

For the constant amplitude (CA) load condition, base material crack growth rate $(d a / d N)_{b}$ is obtained directly from the AFGROW material database, which is $(d a / d N)_{b}$ vs. $\Delta K$. Function $f_{1}(a)$ is obtained by substituting the $\Delta K \sim a$ relation for the $\mathrm{M}(\mathrm{T})$ specimen, eq. (23), into the NASGRO crack growth rate law, eq. (14).

$$
\Delta K=\Delta \sigma \sqrt{\pi a} \sqrt{\sec \left(\frac{\pi a}{W}\right)}
$$


Measured $(d a / d N)_{w}$ data of the test specimen are smoothed to obtain $f_{2}(a)$. The growth rate function $(d a / d N)_{R}$, i.e. $f_{3}(a)$, is obtained by eq. (14) by substituting the nominal $R$ ratio by $R_{\text {eff }}$ in the same equation. Parameters $f$ and $\Delta K_{\text {th }}$ in the NASGRO equation, being functions of $R$, are also modified accordingly. Subsequently, $(d a / d N)_{\text {int }}$ is calculated by eq. (19). Calculated values of $(d a / d N)_{R}$ and $(d a / d N)_{\text {int }}$ are presented in Fig. 6.

For the constant applied $\Delta K$ loading condition (CK), base material crack growth rate $f_{1}(a)$ is constant. Procedure for calculating $(d a / d N)_{R}$ and $(d a / d N)_{\text {int }}$ are the same as for the CA loading case. Two $\Delta K$ values were used, i.e. $\Delta K=6$ and $11 \mathrm{MPa} \sqrt{\mathrm{m}}$, both at $R=0.1$. Calculated crack growth rates are shown in Fig. 7.

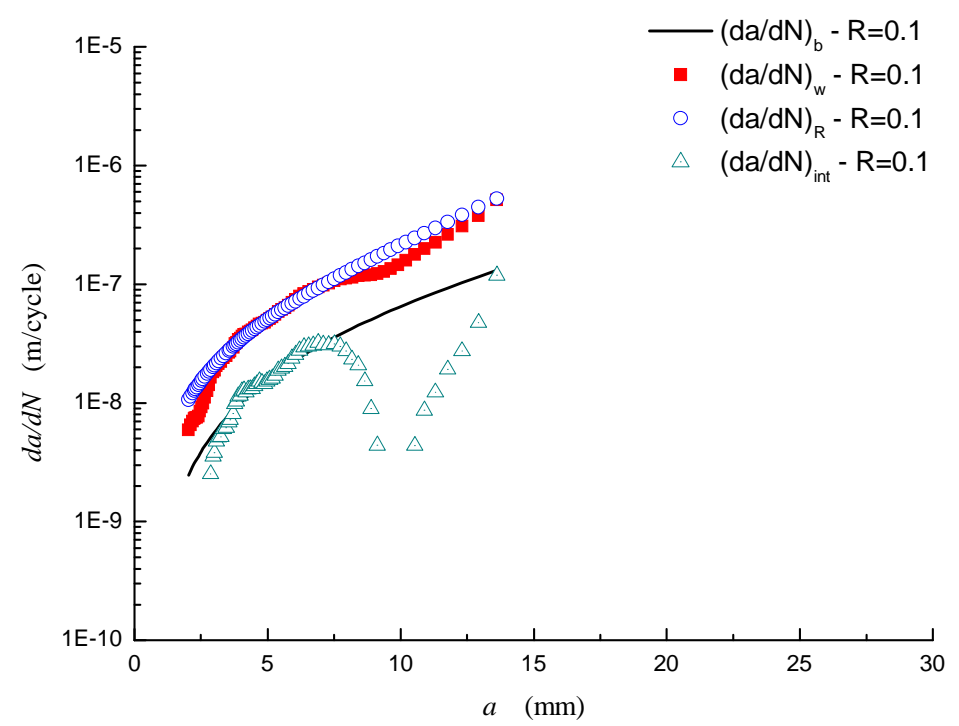

(a)

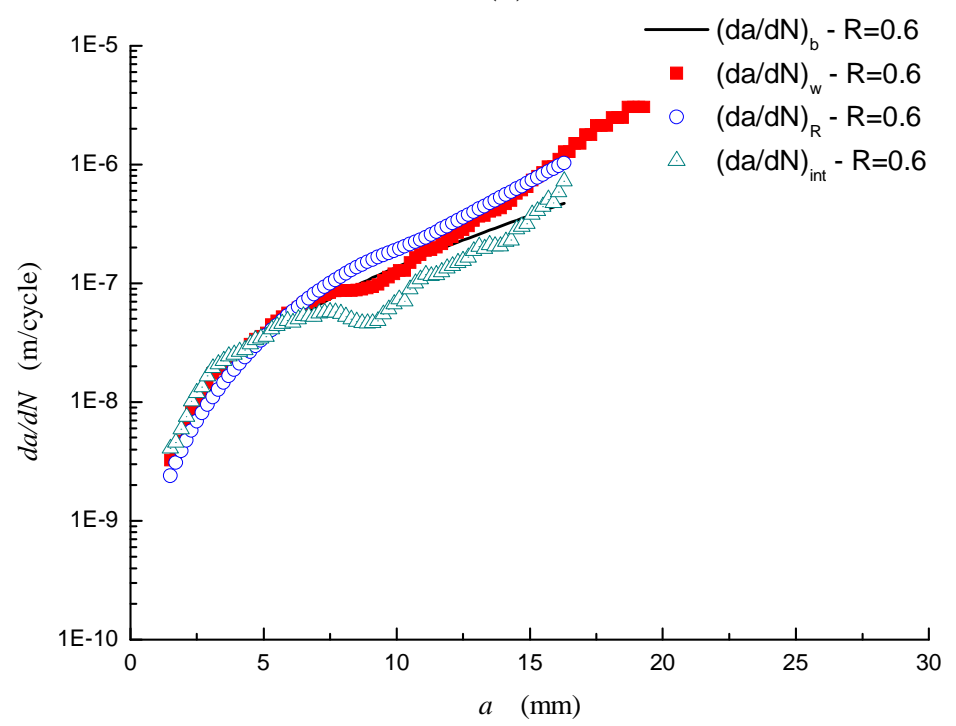

(b)

Fig. 6 Evaluated crack growth rates from constant amplitude load test data under two nominal applied stress ratios: (a) $R=0.1$, (b) $R=0.6$ 


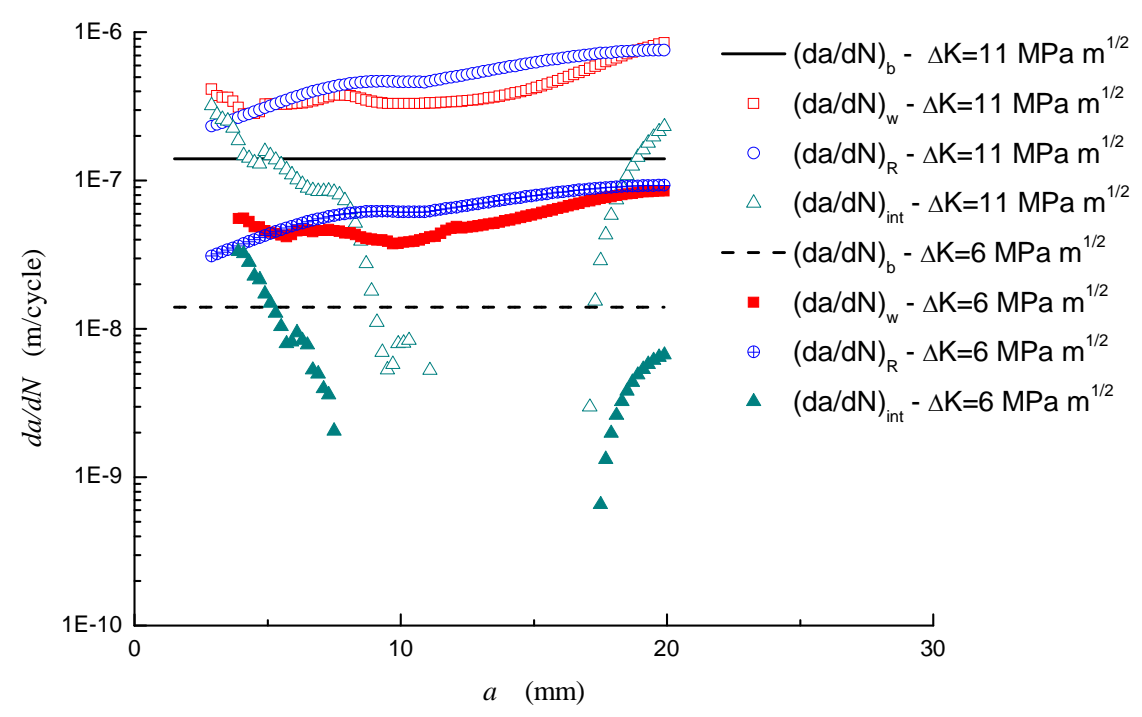

Fig. 7 Evaluated crack growth rates from constant applied $\Delta K$ test data

\section{Discussion}

\subsection{Trend of intrinsic crack growth rate in the longitudinal weld}

Figure 8 presents a comparison of calculated $(d a / d N)_{\text {int }}$ with the hardness and residual stress intensity factor. It shows that the intrinsic crack growth rates exhibit different trends in different weld metal zones. According to the studies performed under the same research programme for the same material and welding process $[22,25]$, the approximate sizes of the three zones are: FZ $(x<5 \mathrm{~mm})$, HAZ $(x=5-30 \mathrm{~mm})$ and BM $(x>30 \mathrm{~mm})$. The total extent of the HAZ is quite large due to the high heat input required to autogeneously weld $12 \mathrm{~mm}$ thick plate (test specimen was skimmed down to $7 \mathrm{~mm}$ in thickness). Since the extent of the HAZ can be estimated from the hardness profile, according to [25], HAZ can be further divided into the so-called "near-HAZ" (5-13 mm from the fusion zone centre) and "far-HAZ" (13-30 $\mathrm{mm}$ ), as marked in Fig. 8c. Following observations have been made on the changes in crack growth rate in the FZ and HAZ.

(1) $\mathrm{FZ}$ and FZ/HAZ transition. Since the half initial crack size was $3 \mathrm{~mm}$, crack growth measurement started from the mid FZ. For the CA case, intrinsic crack growth rate, $(d a / d N)_{\text {int }}$, is the same or slightly higher than that in the base material (Fig. 8a), whereas for the two CK cases, $(d a / d N)_{\text {int }}$ is considerably higher than that of the base material (Fig. 8b). The weld metal exhibits the minimum hardness in this region (labelled I in Fig. 8c). In the early HAZ or the FZ/HAZ transition, $(d a / d N)_{\text {int }}$ decreases to the base material value for the CK case (Fig. 8b), where the hardness quickly increases to a subsidiary peak at $7 \mathrm{~mm}$ (labelled II in Fig. 8c) as the temperature is high enough for hardening-phase re-solution and re-precipitation to occur.

(2) Near-HAZ $(x=7-13 \mathrm{~mm})$. The hardness drops to a further minimum at $11 \sim 12 \mathrm{~mm}$ (labelled III in Fig. 8c) as temperatures here are not sufficiently high to cause re-solution, but still high enough to cause substantial overageing of the base-metal precipitates. Intrinsic crack growth rate decreases significantly to the minimum value; this trend is for both the CA and CK cases (Figs. 8a and 8b). In fact intrinsic growth rate has dropped below the threshold level of the crack growth rate for the CA $R=0.1$ and the two CK cases $(x=10 \mathrm{~mm})$. The reason 
could be the following. Weld metal in this region is much softer and more ductile than that of the base metal. As shown in Fig. 9, yield strength drops to the minimum value of $250 \mathrm{MPa}$ at $9 \mathrm{~mm}$; it returns to the base material value of $370 \mathrm{MPa}$ at about $30 \mathrm{~mm}$ [26]. Because of the low yield strength, crack tip plastic zones are larger in the softer zones resulting in more crack closure and subsequently larger plastic wake behind the advancing crack tip. The consequence of plasticity-induced crack closure is the crack growth retardation or even arrest. This is manifested by the very low or even close-to-zero $(d a / d N)_{\text {int }}$. This trend is most pronounced in the CA load case at $R=0.1$ (due to more crack closure in lower $R$ ratio than the case of $R=$ 0.6) and also in the CK case of at $\Delta K=6$ (due to lower applied $\Delta K$ ). The reason for the physically measureable crack growth rates in the weld, i.e. $(d a / d N)_{w} \approx 10^{-8} \sim 10^{-7}$, is due to the high $K_{\text {res }}$ in the HAZ, Fig. 8d. In the last part of the near-HAZ (11-13 mm), where the hardness and yield strength begin to rise, intrinsic crack growth rate starts to increase. For the two CA cases, growth rate returns to the base metal level. For the $\Delta K=11$ case, the trend of recovery can be observed, but due to the crack closure effect, calculated $(d a / d N)_{\text {int }}$ data is outside the plotting range. For the case of $\Delta K=6$, intrinsic crack growth rate has dropped far too low due to the very low $\Delta K$.

(3) Far-HAZ ( $x>13 \mathrm{~mm}$ ). The hardness is on a rising trend to reach the base-metal value. Although the hardness is still below the base-metal value, there is no further heat effect on the mechanical properties, as the material in this region is overaged at around $13 \mathrm{~mm}$ and then critically aged at about $22.5 \mathrm{~mm}$ [25]. Calculated intrinsic crack growth rates for the CA cases increase to the base material values (at $13-17 \mathrm{~mm}$ ). The growth rate recovery came later for the CK cases (at 19-20 mm). In Fig. 8c, region IV indicates the last part of the far-HAZ, where the temperature is still high enough to cause critical ageing of the base metal precipitate but does not have negative effect on the mechanical properties. Due to the lack of test data for longer crack length (critical half crack length was about $20 \mathrm{~mm}$ in the CA and CK tests), or due to possible data scatter in the test data, it is difficult to judge if the upward trend of $(d a / d N)_{\text {int }}$ at $9 \mathrm{~mm}$ will continue beyond the last calculated data point, in which case it will overshoot the base material curve for both $R$-ratios. Trend in $(d a / d N)_{\text {int }}$ beyond $a=17-20 \mathrm{~mm}$ cannot be established by this study, which is a limitation of this paper.

\subsection{Differences in longitudinal and transverse welds}

For crack propagation perpendicular to a weld, material property changes along the crack path; thus intrinsic crack growth rate changes in different regions across the weld. The method presented in this paper is useful to establish the trend of crack growth rate changes and the influence of weld material property change on FCG rates as demonstrated by Fig. 8 and discussion in Section 4.1.

The methodology and procedure presented in this paper could potentially be more useful for calculating intrinsic crack growth rates for the weld perpendicular to the applied load. In this case intrinsic material property should be constant along the crack growth path. Therefore, a constant $(d a / d N)_{\text {int }}$ should be obtained for constant $\Delta K$. Unfortunately full set of test data (in terms of residual stress, hardness and crack growth rates) was unavailable to this project.

\subsection{Limitations of the method}

Calculated $(d a / d N)_{\text {int }}$ depends on analysis models. In this paper, $(d a / d N)_{R}$ is calculated by the NASGRO equation, which is an empirical crack growth law. Although the effects of $R_{\text {eff }}$, $K_{c}$ and $\Delta K_{t h}$ are all considered in this equation, the law has an inherent limitation for high $R$ ratios. It is found that for many alloys listed in the NASGRO database predicted crack growth rates can be erratic if $R$ is above or below certain values. For example, crack growth rate curves can become vertical when $R>0.7$ [18]. To avoid this, negative and positive cut-off 
a

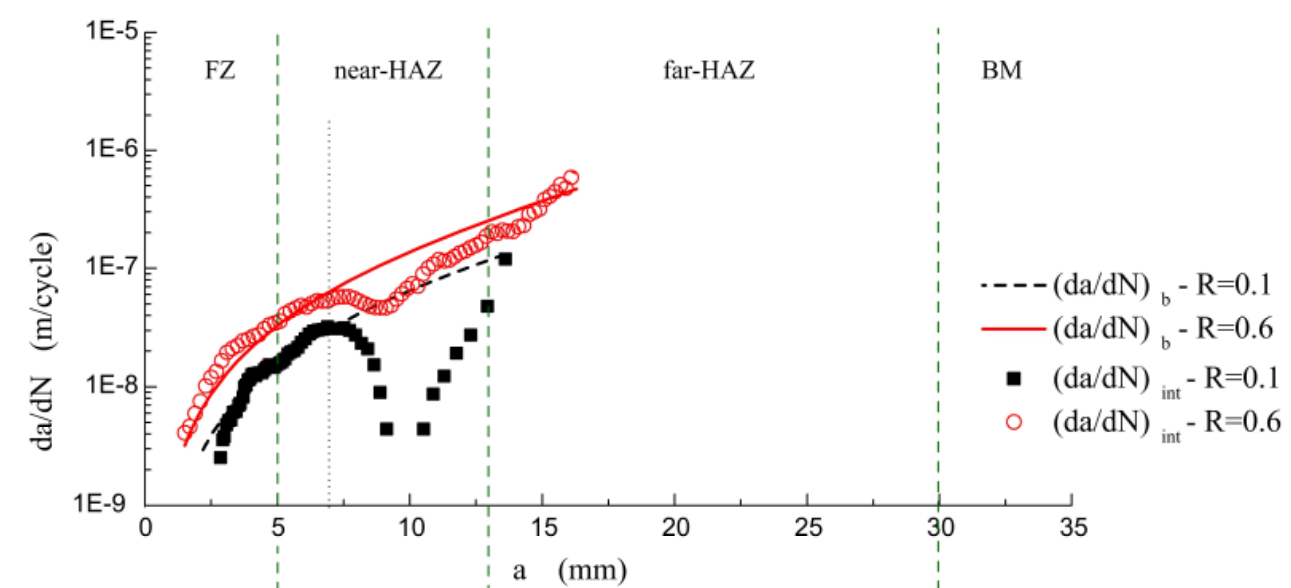

$\mathrm{b}$

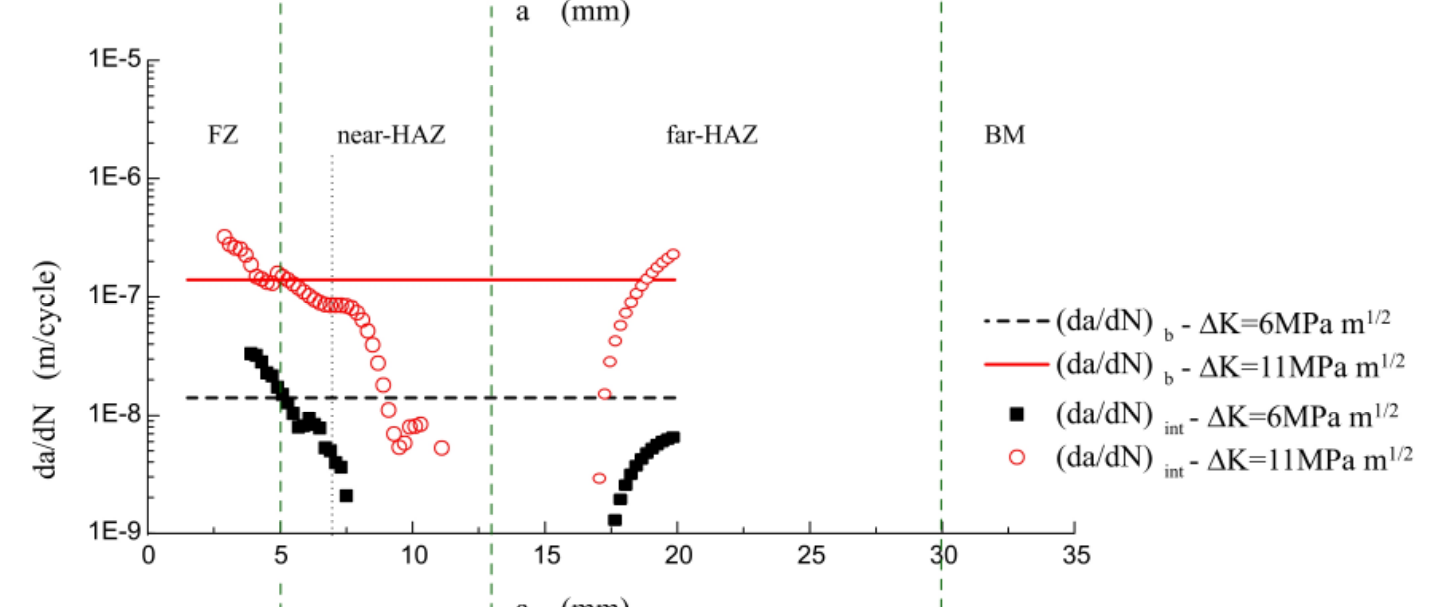

c

a $(\mathrm{mm})$

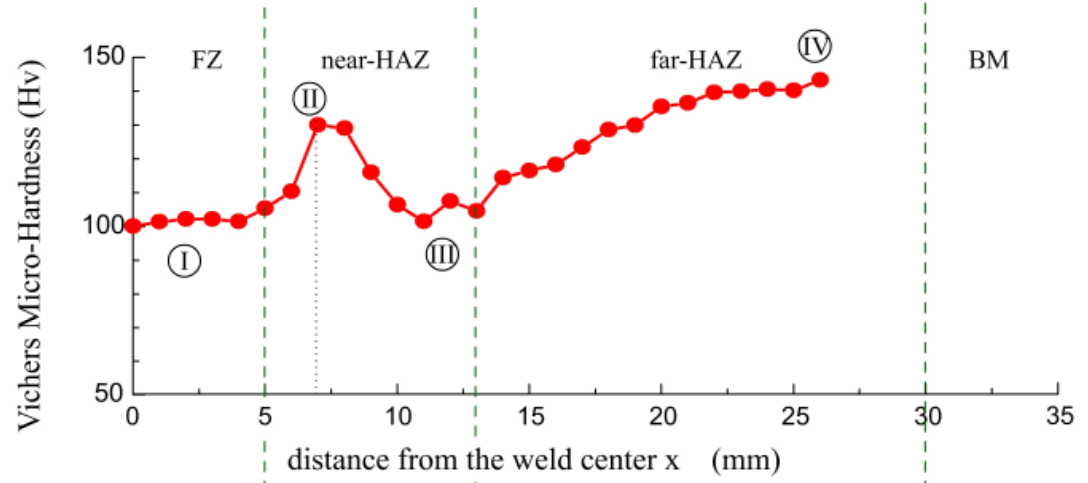

d

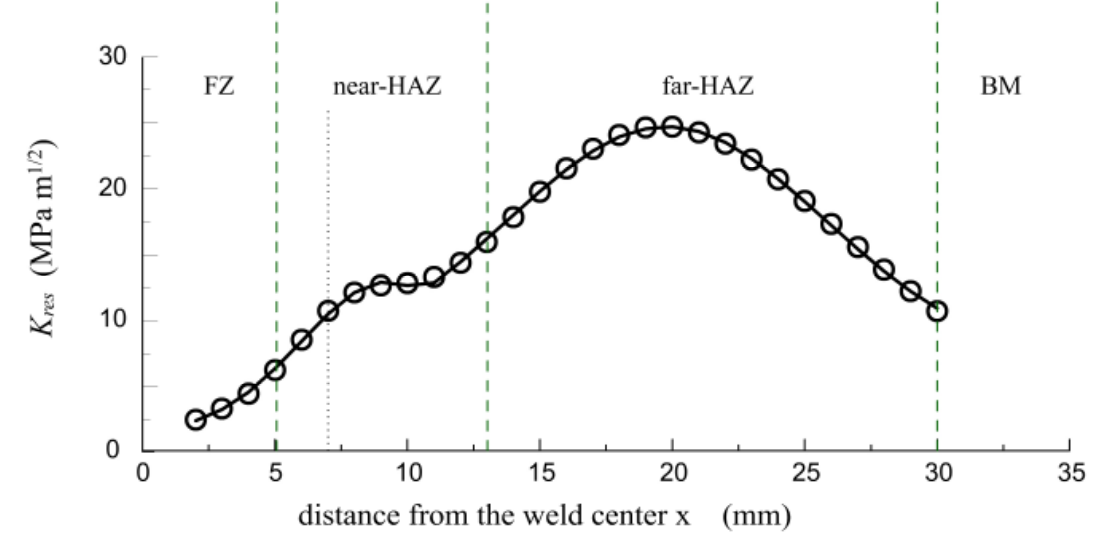

Fig. 8 Calculated intrinsic crack growth rates in (a) constant amplitude load case and (b) constant $\Delta K$ case, (c) micro-hardness profile, (d) residual stress intensity factor. 
stress ratios are set automatically when a material is selected in the AFGROW code. For 2024 -T351, the positive cut-off stress ratio is 0.7 [18]; beyond that infinitely high crack growth rate at a $\Delta K$ will be calculated. Due to the considerably higher residual stresses in this example, Fig. 4 , the effective ratio $R_{\text {eff }}$ are higher than 0.7 for the cases of CA load at nominal $R=0.6$ and CK load at $\Delta K=6$, as shown in Fig. 10. Consequently, $(d a / d N)_{R}$ is overestimated by the NASGRO equation resulting in $(d a / d N)_{\text {int }}$ being underestimated in the region where $R_{\text {eff }}>0.7$. This region corresponds to crack length $a=5-18 \mathrm{~mm}$ for the CA loading at nominal $R=0.6$ and $a=10-18 \mathrm{~mm}$ for the CK $\Delta K=6$ at $R=0.1$. In view of this, calculated $(d a / d N)_{\text {int }}$ data for the cases of CA $R=0.1$ and CK $\Delta K=11$ are used to establish the trend and characteristics of intrinsic crack growth rates in the FZ and HAZ regions. Therefore, when designing experimental tests to evaluate the intrinsic crack growth rate using this method, loading conditions should be considered carefully to ensure the validity of the calculated data.

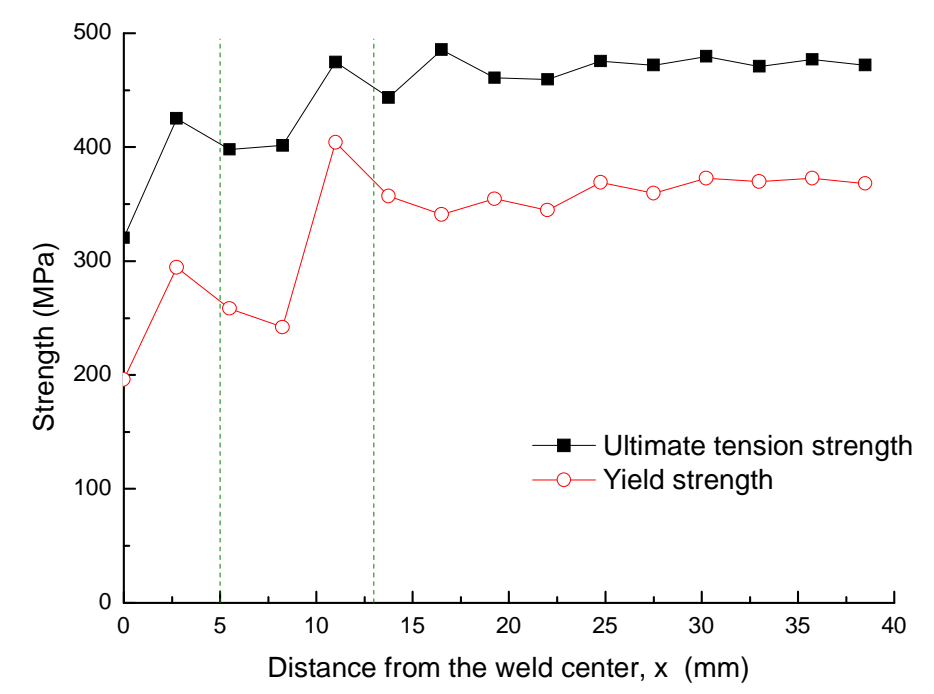

Fig. 9 Changes in yield and ultimate tension strength across the weld [26].

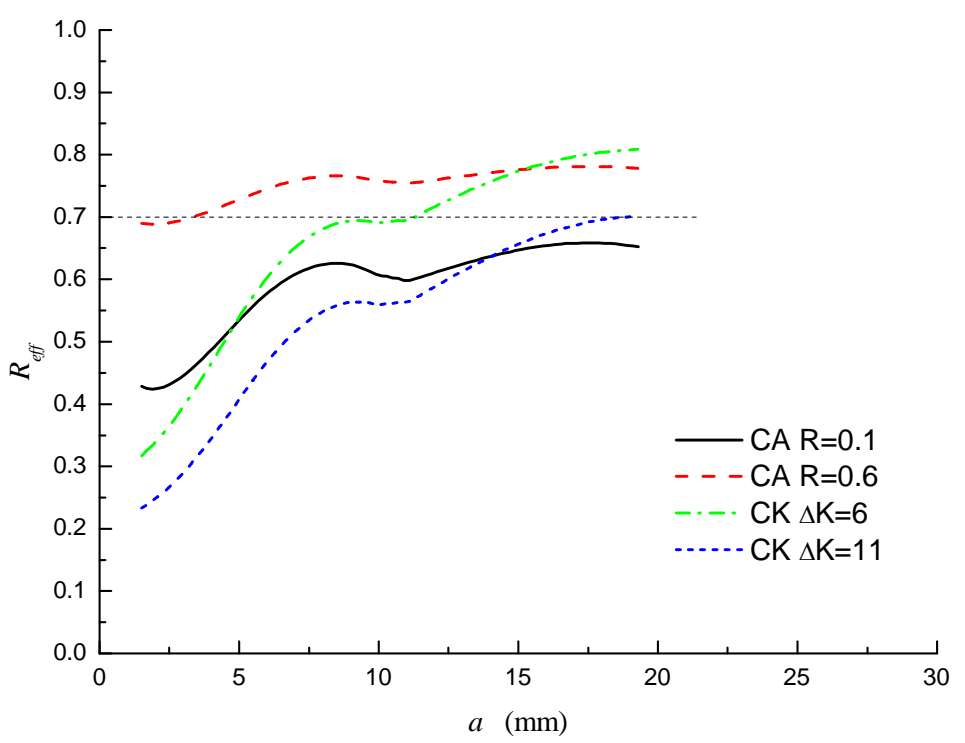

Fig. 10 Calculated effective SIF ratio $\left(R_{e f f}\right)$ for the four loading cases 


\section{Summary}

A method is presented for extracting weld metal crack growth rates from test measured crack growth rates by excluding the influence of welding-induced residual stresses. Calculation procedures are presented and demonstrated via an example of crack propagation across a weld in an $\mathrm{M}(\mathrm{T})$ specimen. Both the constant amplitude and constant stress intensity factor range loading conditions are used.

For crack propagation perpendicular to a weld, trends of crack growth rates in different weld regions are established and compared with changes in the hardness profile, which, to certain extent, reflects the microstructural changes in weld metal. In the fusion zone, crack growth rate is higher than that in the base material; crack growth rate then drops to the base metal level at the FZ/HAZ transition region. Crack growth rate drops further and more significantly in the first part of the near-HAZ due to the much reduced yield strength of the local material. Crack growth rate recovers in the far-HAZ and reaches the base material level as expected. Due to the limitation of the test data, a complete picture of the intrinsic crack growth rate in the far-HAZ and towards base material border could not be obtained from this study.

\section{Acknowledgements}

R Bao thanks the China Scholarship Council for supporting her visit to Cranfield University where this study was performed. Dr S Ganguly's advice on the metallurgical aspects is gratefully acknowledged.

\section{References}

1. Bussu G, Irving PE. The role of residual stress and heat affected zone properties on fatigue crack propagation in friction stir welded 2024-T351 aluminium joints, Int $\mathbf{J}$ of Fatigue, 25 (2003): 77-88.

2. John R, Jata KV, Sadananda K. Residual stress effects on near-threshold fatigue crack growth in friction stir welds in aerospace alloys, Int J Fatigue, 25 (2003): 939-948.

3. Ghidini T, Dalle Donne C. Fatigue crack propagation assessment based on residual stresses obtained through cut-compliance technique, Fatigue \& Fracture of Eng Mater. \& Struct, 30 (2006): 214-222.

4. Edwards L, Fitzpatrick ME, Irving PE, Sinclair I, Zhang X, Yapp D. An integrated approach to the determination and consequences of residual stress on the fatigue performance of welded aircraft structures. J of ASTM International, Vol. 3, Feb 2006; available at www.astm.org.

5. Pacchione M, Werner S, Ohrloff N. Design principles for damage tolerance butt welded joints for application in the pressurized fuselage, Proceedings of 24th Symposium of Int. Committee of Aeronautical Fatigue (ICAF 2007), Naples, 16-18 May 2007.

6. Uz M-V, Koçak M, Lemaitre F, Ehrström J-C, Kempa S, Bron F. Improvement of damage tolerance of laser beam welded stiffened panels for airframes via local engineering, Int $\mathbf{J}$ of Fatigue, 31 (2009) 916-926.

7. Pouget G, Reynolds AP. Residual stress and microstructure effects on fatigue crack growth in AA2025 friction stir welds, Int J Fatigue, 30(2008): 463-472.

8. Fratini L, Pasta S, Reynolds AP, Fatigue crack growth in 2024-T351 friction stir welded joints: longitudinal residual stress and microstructural effects, Int J Fatigue 31(2009): 495500 . 
9. Liljedahl CDM, Brouard J, Zanellato O, Lin J, Tan ML, Ganguly S, et al. Weld residual stress effects on fatigue crack growth behaviour of aluminium alloy 2024-T351. Int J Fatigue, 31(2009): 1081-1088.

10. Beghini M, Bertini L, Vitale E. Fatigue crack growth in residual stress fields: experimental results and modelling, Fatigue \& Fracture of Eng Mater \& Struct, 17(1994): 1433-1444.

11. Itoh YZ, Suruga S, Kashiwaya H. Prediction of fatigue crack growth rate in welding residual stress field, Eng Fract Mech, 33 (1989): 397-407.

12. Servetti G, Zhang X. Predicting fatigue crack growth rate in a welded butt joint: the role of effective $R$ ratio in accounting for residual stress effect. Eng Fracture Mech 76 (2009): 1589-1602.

13. Pirondi A, Collini L, Fersini D. Fracture and fatigue crack growth behaviour of PMMC friction stir welded butt joints, Eng Fract Mech, 75 (2008): 4333-4342.

14. Negre P, Steglich D, Brocks W. Crack extension at an interface: prediction of fracture toughness and simulation of crack path deviation, Int J Fracture, 134 (2005): 209-229.

15. Glinka G. Effect of residual stresses on fatigue crack growth in steel weldments under constant and variable amplitude load. In: Frac. Mech., ASTM STP 677, 1979: 198-214.

16. Parker AP. Stress intensity factors, crack profiles, and fatigue crack growth rates in residual stress fields. In: Residual Stress Effects in Fatigue, ASTM STP 776, American Society for Testing and Materials, 1982, pp. 13-31.

17. Walker K. The effect of the stress ratio during crack propagation and fatigue for 2024-T3 and 7075-T6 aluminium. ASTM STP 462, vol. 462, Effects of environment and complex load history on fatigue life, pp. 1-14. 1970.

18. Harter JA. AFGROW users guide and technical manual, AFRL-VA-WP-TR-2006-XXXX, AFGROW for Windows 2K/XP, Version 4.0011.14, June 2006. Website (accessed July 2008): http://www.siresearch.info/projects/afgrow/downloads/afgrow/ddownload.php.

19. Forman RG, Kearney VE, Engle RM. Numerical analysis of crack propagation in a cyclic loaded structure. ASME Trans. J Basic Eng, 89D (1967), p. 459.

20. Anderson TL. Fracture Mechanics: Fundamentals and Applications. Third Edition. CRC Taylor \& Francis. 2005.

21. Hou R, Evans DM, McClure JC, Nunes AC, Garcia G. Shielding gas and heat transfer efficiency in plasma arc welding, Welding Journal, 75 (1996), S305-S310.

22. Lefebvre F. Micromechanical assessment of fatigue in airframe fusion welds. PhD Thesis. University of Southampton, U.K., 2003.

23. Brouard J, Lin J, Irving PE. Effects of residual stress and fatigue crack closure during fatigue crack growth in welded 2024 aluminium. In : Proc. of Fatigue 2006, June 2006, Atlanta, USA.

24. R Bao, X Zhang, W Ahmed Yahaya. Evaluating stress intensity factors due to weld residual stresses by the weight function and finite element methods, Eng Fract Mech, 77 (2010) 2550-66.

25. Ganguly S, Fitzpatrick ME, Edwards L. Use of neutron and synchrotron X-ray diffraction for evaluation of residual stresses in a 2024-T351 aluminium alloy variable-polarity plasmaarc weld, Metallurgical \& Materials Transactions A, 37A (2006): 411-420.

26. Ganguly, S. Non-destructive measurement of residual stresses in welded aluminium 2024 airframe alloy, PhD Thesis, Open University, U.K. 2004. 